\title{
The use of topical calcineurin inhibitors for pyoderma gangrenosum in inflammatory bowel disease: A case series
}

\author{
Poornima Varma ${ }^{1,2 *}$, Ashley Bloom ${ }^{1}$, Kurvi Patwala ${ }^{2}$, Kristin Taylor ${ }^{3}$, Peter De Cruz ${ }^{2}$, Miles Sparrow and Stephen Pianko ${ }^{1}$ \\ ${ }^{1}$ Department of Gastroenterology, Level 3, Monash Medical Centre, 246 Clayton Road, Clayton VIC 3168, Australia \\ ${ }^{2}$ Department of Gastroenterology, Level 8 Harold Stokes Building, Austin Hospital, 145 Studley Road, Heidelberg, VIC 3084, Australia \\ ${ }^{3}$ Department of Gastroenterology, and Monash University, Alfred Hospital, 55 Commercial Rd, Melbourne VIC 3004, Australia
}

\begin{abstract}
Pyoderma gangrenosum (PG) is an uncommon skin condition that is seen in patients as a systemic manifestation of malignancy, inflammatory bowel disease (IBD) and other autoimmune diseases. There are many local and systemic therapies available in the treatment of PG; however, there is a lack of high-quality evidence regarding their efficacy. Tacrolimus and Pimecrolimus are calcineurin inhibitors which have demonstrated good efficacy in the management of PG based on small studies and case reports. We report six cases of PG in anti-TNF naive and experienced IBD patients, successfully managed with topical calcineurin inhibitors.
\end{abstract}

\begin{abstract}
Abbreviations: anti-IL: Anti-Interleukin; anti-TNF: anti-tumour necrosis factor alpha; CNI: Calcineurin Inhibitor; CD: Crohn's Disease; IBD: Inflammatory Bowel Disease; PPG: Peristomal Pyoderma Gangrenosum; PG: Pyoderma Gangrenosum; UC: Ulcerative Colitis.

\section{Introduction}

Pyoderma gangrenosum (PG) is an uncommon skin disorder that can occur as a systemic manifestation of inflammatory bowel disease (IBD) $[1,2]$. PG is characterized clinically by recurrent painful and purulent ulcers, and histologically by neutrophil accumulation in the skin ${ }^{[1]}$. The lesions can occur at areas of skin trauma such as colostomy or ileostomy sites, or in normal skin. Multiple local and systemic therapies have been used in the treatment of PG; however, there is a paucity of high-quality evidence regarding their efficacy. Topical and systemic corticosteroids, topical tacrolimus and pimecrolimus, and systemic cyclosporine are most commonly used, alongside thiopurines and anti-tumour necrosis factor alpha (anti-TNF) agents. Tacrolimus and Pimecrolimus are calcineurin inhibitors (CNI) frequently used in the transplant setting, which act by inhibiting T-cell proliferation and activation ${ }^{[2]}$. These agents have shown good efficacy in the management of PG with improvement seen as early as week one post topical CNI commencement [3]. We present our experience of topical CNI use in six patients with IBD.
\end{abstract}

\section{Case reports}

The cases are summarised in table 1. First is a 36-year-old antiTNF naive female with stricturing and perianal $C D$, who developed a $3 \mathrm{~cm}$ histologically confirmed PG lesion on her right thigh whilst on 6-mercaptapurine and prednisolone. This was managed with pimecrolimus $1 \%$ cream twice daily for 13 weeks. First clinical response was seen at week one with complete resolution by week 13 . She developed a recurrence at 12 months; however, responded to pimecrolimus again with complete resolution over 4 weeks, and is in remission.

The second case is a 36-year-old anti-TNF experienced female with IBD-unclassified requiring a colectomy and ileostomy for a severe exacerbation. She developed $>10 \mathrm{cms}$ of peristomal PG (PPG) later that year whilst off therapy. Initial treatment included 2 weeks of colchicine and topical diprosone plus 4 weeks of topical betamethasone with persistent disease. She then escalated to tacrolimus ointment $0.1 \%$ daily for 18 weeks, plus topical diprosone and oral colchicine 2 weeks after tacrolimus commencement. The lesion improved significantly within 4 weeks allowing reversal of the stoma. There was no recurrence at the time of surgery 10 weeks later or at post-op follow-up.

The third case is a 30-year-old anti-TNF experienced female with severe structuring $\mathrm{CD}$ requiring two small bowel resections, a right hemicolectomy and end-ileostomy. She developed PPG (>10 $\mathrm{cm}$ ) in 2013 whilst on adalimumab $40 \mathrm{mg}$ weekly, azathioprine and prednisolone. This was managed for 18 months with a combination of clobetasol ointment, four subcutaneous steroid injections, colchicine and cephalexin. She relapsed in 2015 and was treated with tacrolimus ointment $0.1 \%$ second daily with two weeks to first clinical response and is currently at week 7 with a healing lesion.

The fourth case is a 33-year-old male with severe left sided Crohn's colitis and multiple extra-intestinal manifestations of IBD, in clinical remission on prednisolone, sulfasalazine and azathioprine. He relapsed post-withdrawal of azathioprine and underwent a resection and endileostomy. Initial therapy included antibiotics for peristomal lesions and infliximab for worsening disease. Despite minor improvement, the peristomal lesion progressed to $>10 \mathrm{~cm}$ in size and was consistent with PG. He was then trialed on topical tacrolimus $0.3 \%$ whilst on infliximab

*Correspondence to: Poornima Varma, Department of Gastroenterology, Level 3, Monash Medical Centre, 246 Clayton Road, Clayton VIC 3168, Australia, Tel: (03) 9594 3177, Fax: (03) 9594 6250; E-mail: poornima.varma@monashhealth.org

key words: calcineurin inhibitors, inflammatory bowel disease, peristomal pyoderma gangrenosum, pyoderma gangrenosum, pimecrolimus, tacrolimus

Received: January 03, 2020; Accepted: January 17, 2020; Published: January 20, 2020 
Table 1. Basic demographics and details of the six patients with PG

\begin{tabular}{|c|c|c|c|c|c|c|c|c|c|}
\hline Case & Age, Gender & $\begin{array}{c}\text { CD Montreal } \\
\text { Classification } \\
{[20]}\end{array}$ & $\begin{array}{c}\text { Year of PG } \\
\text { diagnosis }\end{array}$ & Site of PG & $\begin{array}{c}\text { Pervious PG } \\
\text { Treatment }\end{array}$ & Topical CNI & $\begin{array}{c}\text { Time to First } \\
\text { Response } \\
\text { (Weeks) }\end{array}$ & $\begin{array}{l}\text { Duration of } \\
\text { Treatment } \\
\text { (weeks) }\end{array}$ & $\begin{array}{c}\text { Complete } \\
\text { Resolution at } \\
\text { Last Follow-up }\end{array}$ \\
\hline 1 & $36, \mathrm{~F}$ & $\mathrm{~A} 2, \mathrm{~L} 2, \mathrm{~B} 2 \mathrm{P}$ & 2008 & Other & No & Pimercrolimus & 1 & 13 & $\begin{array}{c}\text { Recurrence at } \\
1 \text { year }\end{array}$ \\
\hline 2 & $36, \mathrm{~F}$ & $\mathrm{~A} 2, \mathrm{~L} 1, \mathrm{~B} 1$ & 2014 & Peristomal & Yes & Tacrolimus & 4 & 18 & Yes \\
\hline 3 & $30, \mathrm{~F}$ & $\mathrm{~A} 2, \mathrm{~L} 3, \mathrm{~B} 2$ & 2015 & Peristomal & Yes & Tacrolimus & 2 & 7 & Yes \\
\hline 4 & $33, \mathrm{M}$ & $\mathrm{A} 2, \mathrm{~L} 3, \mathrm{~B} 3 \mathrm{p}$ & 2016 & Peristomal & No & Tacrolimus & 2 & 5 & Recurrence* \\
\hline 5 & $35, \mathrm{~F}$ & $\mathrm{~A} 2, \mathrm{~L} 3, \mathrm{~B} 3 \mathrm{p}$ & 2000 & Peristomal & No & Pimercrolimus & 8 & 8 & Yes \\
\hline 6 & $27, \mathrm{~F}$ & $\mathrm{~A} 2, \mathrm{~L} 3 / 4, \mathrm{~B} 2 / 3 \mathrm{p}$ & 2005 & Peristomal & No & Pimercrolimus & 2 & 18 & Yes \\
\hline
\end{tabular}

*Recurrence in the setting of premature cessation of treatment and intermittent use by the patient

and methotrexate. There was complete resolution by week 5 at which point the patient self-ceased the tacrolimus. He then developed peristomal recurrence but recaptured response rapidly.

The fifth case is a 35-year-old anti-TNF naïve female with Crohn's disease requiring an ileostomy and small bowel resection following drainage of an intra-abdominal collection. She later developed PPG $(<5$ $\mathrm{cm}$ ) whilst on azathioprine. Pimecrolimus $1 \%$ daily was trialed with complete resolution over an 8 -week period and no recurrence to date.

The last case is a 27-year-old anti-TNF experienced female with severe fistulising and structuring Crohn's disease, needing an ileocecal resection, subtotal colectomy and subsequently a completion proctocolectomy and ileostomy. She later developed PPG $(<5 \mathrm{c})$ whilst on 8-weekly Vedolizumab and was commenced on pimecrolimus $1 \%$ daily with complete resolution over 18 weeks. First clinical response was seen at week 2 . There have been no recurrences.

Long-term effects are yet to be determined but none of our cases experienced any side-effects to either CNI.

\section{Discussion}

PG is an uncommon, inflammatory ulcerative skin disorder that is often difficult to treat. It commonly occurs at sites of minor trauma as a tender inflammatory nodule or pustule that breaks down to create a necrotic ulcer [4]. PG can occur in patients with IBD and is thought to account for approximately $50 \%$ of chronic parastomal ulcers in IBD $[2]$.

Currently no guidelines exist for the management of PG however many treatments have been trialed including systemic and topical corticosteroids, oral immunosuppressants including thiopurines and anti-TNF agents and intravenous immunoglobulin. Surgery alone has not shown good efficacy in PG [4]. Of the medical options, there have been few case reports and randomised controlled trials demonstrating a favourable response to anti-TNF therapy including infliximab, etanercept, and adalimumab $[4,5]$. Newer biologics such as ustekinumab (anti-IL-23), ixekizumab (anti-IL-17) and brodalumab (anti-IL17R) are also showing benefit given the effect of IL-17 on neutrophil migration [4]. Amongst these agents, infliximab has been most studied in PG. In a randomized, placebo-controlled study, patients treated with infliximab ( $5 \mathrm{mg} / \mathrm{kg}$ every 2 weeks) had significant improvement compared to placebo at 2 weeks ( $46 \%$ vs $6 \%, p=0.025)$. There was a $21 \%$ remission rate at 6 weeks $[4,6]$. Although limited in comparison, the evidence for topical CNI in PG, even in anti-TNF refractory disease is promising. There are multiple case reports, few prospective case series, and uncontrolled studies which show improvement in PGrelated ulcers in both anti-TNF naïve and experienced patients with topical CNI use. Pimecrolimus ( $1 \%$ cream) and tacrolimus $(0.03 \%$ and $0.1 \%$ ointment) are topical, non-steroidal calcineurin inhibitors most commonly used and studied in the treatment of atopic dermatitis (AD) with good efficacy [7].

In PG, topical tacrolimus has been used in concentrations of $0.03 \%$ up to $0.3 \%$ in a compounded formulation and has shown excellent results in many case reports and small studies [2,3,8-10]. Clinical improvement is variable and has been reported to occur within a few days, but can take several weeks to months [2,3,9-12]. In one study by Lyon et al. [9] 11 patients with PPG received treatment with topical tacrolimus $0.3 \%$ and 13 with topical clobetasol propionate $0.05 \%$ as monotherapy. Seven of the tacrolimus-treated patients had complete healing (mean time to healing 5.1 weeks) compared with five of the clobetasol propionate-treated group (mean 6.5 weeks). In six other patients, who had failed to respond adequately to multiple systemic and topical treatments for PPG, the addition of topical tacrolimus was associated with healing within 6 weeks [9]. Thomas et al. [12] prospectively studied outcomes with topical therapies, including tacrolimus $0.03 \%$ or $0.1 \%$ in 66 patients. Of the 10 tacrolimus-treated patients, 5 achieved complete healing by 6 months (mean 161 days to healing). There was no recurrence at follow-up ranging from 5.5 to 37.2 months after healing [12]. Although the optimal strength and minimum duration for topical tacrolimus has not been outlined, our case series is in keeping with the existing evidence for the use of $0.03 \%$ to $0.1 \%$ topical tacrolimus for PG, with observed clinical response as early as 2 weeks.

Pimecrolimus may also have benefit for PG; however, there is less evidence available on its' use, which is limited to two case reports $[13,14]$. In both cases there was no recurrence at 12-month followup. These two case reports and our series support the trial of topical pimecrolimus in the management of PG.

In contrast to oral CNI, systemic absorption of topical CNI is reportedly low hence monitoring of serum levels and renal function is not routinely performed. In studies of children with $92 \%$ of body surface area affected with $\mathrm{AD}, 67 \%$ had pimecrolimus blood concentrations (BC) $<0.5 \mathrm{ng} / \mathrm{ml}$ and $97 \%$ of $\mathrm{BC}<0.5-2.0 \mathrm{ng} / \mathrm{ml}$. Similarly, in studies of tacrolimus $0.1 \%$ ointment in adults with $\mathrm{AD}$, in 45 of 49 patients tacrolimus levels reached peak $\mathrm{BC}<5 \mathrm{ng} / \mathrm{ml}$ [15-18]; however, significant systemic absorption of tacrolimus has been described in patients with other skin disorders [15]. There is one reported case of topical tacrolimus causing temporary renal failure in a 50 -year-old male who used equivalent of $60 \mathrm{mg}$ of tacrolimus per day for multilocal PG. Despite needing dialysis, he was discharged within 6 days with restored renal function $[19,20]$. Pimecrolimus' penetration through the skin is very low, lower than tacrolimus and much lower than topical corticosteroids. Even occlusive treatment with pimecrolimus cream showed no measurable increase in its BC [15]. Given the similar mode of action as tacrolimus with less skin penetration, pimecrolimus is likely to be just as efficacious, and provides an alternate topical solution to a difficult management problem. 


\section{Conclusion}

PG is an uncommon dermatological disorder, more commonly seen in patients with IBD, malignancy or autoimmune diseases. Despite effective management options for these conditions, PG remains difficult to treat. Although other therapies, particularly anti-TNF agents, have proven efficacy in IBD patients, previous reports and our case series are showing promise for the use of topical CNIs in the management of anti-TNF naïve and refractory PG. The long-term side-effect profile is yet to be determined; however, tacrolimus and pimecrolimus provide a cost-effective topical solution to a localized disorder, which may also limit the risks associated with additional or accelerated systemic immunosuppression.

\section{References}

1. Marzano AV, Ishak RS, Saibeni S, Crosti C, Meroni PL, et al. (2013) Autoinflammatory skin disorders in inflammatory bowel diseases, pyoderma gangrenosum and Sweet's syndrome: a comprehensive review and disease classification criteria. Clin Rev Allergy Immunol 45: 202-210. [Crossref]

2. Altieri M, Vaziri K, Orkin BA (2010) Topical tacrolimus for parastomal pyoderma gangrenosum: a report of two cases. Ostomy Wound Manage 56: 56-59. [Crossref]

3. Khurrum Baig M, Marquez H, Nogueras JJ, Weiss EG, Wexner SD (2004) Topical tacrolimus (FK506) in the treatment of recalcitrant parastomal pyoderma gangrenosum associated with Crohn's disease: report of two cases. Colorectal Dis 6: 250-253. [Crossref]

4. Patel F, Fitzmaurice S, Duong C, He Y, Fergus J, et al. (2015) Effective Strategies for the Management of Pyoderma Gangrenosum: A Comprehensive Review. Acta Derm Venereol 95: 525-531. [Crossref]

5. Jaimes-López N, Molina V, Arroyave JE, Vasquez LA, Ruiz AC, et al. (2009) Development of pyoderma gangrenosum during therapy with infliximab. $J$ Dermatol Case Rep 3: 20-23. [Crossref]

6. Brooklyn TN, Dunnill MG, Shetty A, Bowden JJ, Williams JD, et al. (2006) Infliximab for the treatment of pyoderma gangrenosum: a randomised, double blind, placebocontrolled trial. Gut 55: 505-509. [Crossref]

7. Paller AS, Lebwohl M, Fleischer AB, Jr, Antaya R, Langley RG, et al. (2005) Tacrolimus ointment is more effective than pimecrolimus cream with a similar safety profile in the treatment of atopic dermatitis: results from 3 randomized, comparative studies. J Am Acad Dermatol 52: 810-822. [Crossref]
8. Rispo A, Testa A, Diaferia M, Castiglione F, Lo Presti M (2009) Monster parastomal pyoderma gangrenosum effectively treated by topical tacrolimus. J Crohns Colitis 3 : 218-219. [Crossref]

9. Lyon CC, Stapleton M, Smith AJ, Mendelsohn S, Beck MH, et al. (2001) Topical tacrolimus in the management of peristomal pyoderma gangrenosum. $J$ Dermatolog Treat 12: 13-17. [Crossref]

10. Marzano AV, Trevisan V, Lazzari R, Crosti C (2010) Topical tacrolimus for the treatment of localized, idiopathic, newly diagnosed pyoderma gangrenosum. $J$ Dermatolog Treat 21: 140-143. [Crossref]

11. Kimble RM, Tickler AK, Nicholls VS, Cleghorn G (2002) Successful topical tacrolimus (FK506) therapy in a child with pyoderma gangrenosum. J Pediatr Gastroenterol Nutr 34: 555-557. [Crossref]

12. Thomas KS, Ormerod AD, Craig FE, Greenlaw N, Norrie J, et al. (2016) Clinical outcomes and response of patients applying topical therapy for pyoderma gangrenosum: A prospective cohort study. J Am Acad Dermatol 75: 940-949. [Crossref]

13. Bellini V, Simonetti S, Lisi P (2008) Successful treatment of severe pyoderma gangrenosum with pimecrolimus cream 1\%. J Eur Acad Dermatol Venereol 22: 113115. [Crossref]

14. Cecchi R, Pavesi M, Bartoli L, Brunetti L (2012) Successful treatment of localized pyoderma gangrenosum with topical pimecrolimus. J Cutan Med Surg 16: 295-297. [Crossref]

15. Czarnecka-Operacz M, Jenerowicz D (2012) Topical calcineurin inhibitors in the treatment of atopic dermatitis - an update on safety issues. J Dtsch Dermatol Ges 10 : 167-172. [Crossref]

16. Hultsch T, Kapp A, Spergel J (2005) Immunomodulation and safety of topical calcineurin inhibitors for the treatment of atopic dermatitis. Dermatology 211: 174187. [Crossref]

17. Thaçi D, Salgo R (2010) Malignancy concerns to topical calcineurin inhibitors for atopic dermatitis: facts and controversies. Clin Dermatol 28: 52-56. [Crossref]

18. Bonacier L, Charlesworth EN, Spergel JM, Leung DY (2006) The black box warning for topical celcineurin inhibitors: looking outside the box. Ann Allergy Asthma Immunol 97: 117-120. [Crossref]

19. Wollina U (2013) Letter to the editor: Temporary renal insufficiency associated with topical tacrolimus treatment of multilocal pyoderma gangrenosum. $J$ Dermatol Case Rep 7: 106-107. [Crossref]

20. Satsangi J, Silverberg MS, Vermeire S, Colombel JF (2006) The Montreal classification of inflammatory bowel disease: controversies, consensus, and implications. Gut 55: 749-753. [Crossref]

Copyright: (C2020 Varma P. This is an open-access article distributed under the terms of the Creative Commons Attribution License, which permits unrestricted use, distribution, and reproduction in any medium, provided the original author and source are credited. 